\title{
Factors that influence the quality of worklife of first-line nurse managers in a French Canadian Healthcare system
}

\author{
Sylvain Brousseau*1, Chantal Cara², Régis Blais ${ }^{3}$ \\ ${ }^{1}$ Department of Nursing Science and Director of Health Sciences, Université du Québec en Outaouais, Saint-Jérôme, Québec, \\ Canada \\ ${ }^{2}$ Faculty of Nursing Science, Université de Montréal, Montréal, Québec, Canada and Distinguished Caring Science Scholar, \\ Watson Caring Science Institute, Colorado, USA \\ ${ }^{3}$ Health public school, Department of Management, Evaluation and Health Policy, Université de Montréal, Montréal, Québec, \\ Canada
}

Received: May 6, 2019

DOI: $10.5430 /$ jha.v8n4p1
Accepted: May 26, 2019

URL: https://doi.org/10.5430/jha.v8n4p1
Online Published: May 30, 2019

\begin{abstract}
$\operatorname{Aim}(\mathbf{s}):$ This quantitative study sought to explore the factors that influence positively and negatively the quality of work life (QWL) of first-line nurse managers (FLNMs) among healthcare institutions from a humanistic standpoint.

Background: In Canada, the public healthcare reforms have had a considerable impact on FLNMs, which could have a negative effect on the FLNMs' QWL.

Method: A quantitative descriptive design was conducted with FLNMs ( $\mathrm{n}=291)$ using a Web online survey to identify the factors that influenced favorably and unfavorably the FLNMs' QWL. A statistical analysis (SPSS software, version 22 for Windows 7) of Quebec's French Web survey questionnaire highlight was used to conduct this descriptive study.

Results: The quantitative results show some significant connections between socio-demographic characteristics, such as age and years of experience, and the choice of factors that affect QWL of FLNMs. The most important favourable factors were the actualization of leadership and political skills to improve quality of nursing, the contextual elements conducive to organizational humanization and the organizational support promoting personal and socioprofessional fulfillment. On the opposite, the main unfavourable factors were the organizational dehumanization, the undesirable working conditions in nursing management and the insufficient coaching of novice nurse managers.

Conclusion: Healthcare organizations should develop a QWL program and policies to provide information on nursing management humanistic practices. These findings enable us to provide recommendations in the fourth domains of nursing practice.

Implications for nursing management: Healthcare administrators must consider strategies to maximize the QWL of the next generation of FLNMs in healthcare institutions.
\end{abstract}

Key Words: Firstline nurse managers, Quality of working life, Quantitative method

\section{INTRODUCTION}

The public healthcare systems have undergone a series of organizational restructuring initiatives in the name of economic rationality. These reforms have had a considerable impact on first-line nurse managers (FLNMs) in numerous countries, ${ }^{[1]}$ gradually undermining the foundations of their work in these

*Correspondence: Sylvain Brousseau; Email: sylvain.brousseau @uqo.ca; Address: 5, Saint-Joseph street, Saint-Jérôme, Québec J7Z0B7, Canada. 
systems. According to Levin, ${ }^{[2]}$ structural and administrative reorganization has resulted in accrued decision-making authority in appearance only and a shift in role and responsibilities for FLNMs towards purely administrative duties, leaving little room for clinical activities. Brown et al., ${ }^{[3]}$ asserted that supervisory activities were steadily increasing in intensity and that employment equity between FLNMs was not always a given, which could have a negative effect on the attraction and retention of these professionals in nursing management.

\subsection{Background}

In the past decade, FLNMs have seen their working conditions deteriorate gradually, which might explain the greater turnover, absenteism, and psychological distress observed among these managers. ${ }^{[1]}$ Driven by economic concerns, the multiple structural changes within the healthcare system were characterized by cuts in the number of supervisory positions and a considerably higher ratio of nurses to nurse managers, ${ }^{[4]}$ meaning more staff to supervise on care units for the remaining FLNMs. ${ }^{[3]}$ As a corollary to these changes, healthcare policy-makers have accentuated the accountability of FLNMs. More specifically, according to Shirey et al., ${ }^{[5]}$ FLNMs suddenly find themselves having to answer for attaining organizational objectives they had no say in setting, enjoying little real decision-making power, and operating under increasingly chaotic working conditions of the FLNMs. These elements suggest that the difficult professional conditions, reported in many studies cited earlier, could have a negative impact on the FLNMs' QWL.

\subsection{Litterature review}

The literature confirms that new-generation nurses, aspiring to a career in management, are questioning the relevance of embarking upon that path, given the workload and the uncertainty generated by the multiple structural changes to the healthcare system. ${ }^{[4,7]}$ A Canada-wide survey of staff nurses revealed that only $24 \%$ wished to pursue a career in nursing management. ${ }^{[8]}$ A prospective study conducted in Sweden showed that $40 \%$ of FLNMs in the healthcare field quit their management position within four years. ${ }^{[9]}$ The daily work performed by FLNMs is of great importance in healthcare institutions. ${ }^{[10]}$ According to them, it consists of managing clinical care activities, human, financial, and material resources, as well as providing mentorship to novice staff nurses. In addition to reporting to their employer, FLNMs must, in particular, ensure an optimum work environment and defend the quality and safety of care delivered by their unit or department. They must assure their professional administrative competencies are constantly up to date in order to manage their departments efficiently and thus make the best possible decisions based on evidence. ${ }^{[10]}$

Furthermore, FLNMs also act as contacts and spokespersons for both staff nurses and service users, using their leadership and political clout to push management issues forward. ${ }^{[1]}$ Moreover, it seems that the work context of FLNMs represent an obstacle to the maintenance and the optimization of their QWL. It seems that all these factors are combined to muddy their professional identity and, by the same token, to bring about a resurgence of work-related health problems, such as distress, burnout, and stress. ${ }^{[6]}$ To our knowledge, quantitative scientific literature on QWL have, for the most part, investigated this concept among nursing staff, excluding FLNMs and humanistic management practice variables. In sum, most of the research among nurses to management positions are well documented; however, all of them did not study the factors that influence favorably and unfavorably the QWL of FLNMs from a humanistic view.

\subsection{Theoretical framework}

\subsubsection{Quality of nursing worklife's model}

O'Brien-Pallas and Baumann ${ }^{[11]}$ defined QWL as the influence of individual, social, and organizational factors on the context of nurses' work as well as on the outcomes of patient care. Since no framework for QWL specific to FLNMs was availaible, the one chosen for the purpose of this study was a model designed for staff nurses by O'Brien-Pallas and Baumann. ${ }^{[1]}$ This framework situates a nurse's work within the person's social and cultural context. It draws a connection between the personal experience of nurses and the socio-economic context, including government policies and economic environment, which influence decisions regarding healthcare organizations. The model is composed of two sets of factors-external and internal-capable of influencing QWL. The external factors encompass the labor market, decision-making policies respecting healthcare, and the demands of service users. The internal factors include administrative, operational, socio-environmental, contextual, and personal factors.

\subsubsection{The Watson's Human Caring theory}

The Human Caring theory, developed by nursing theorist Jean Watson, ${ }^{[12,13]}$ is an intersubjective human-to-human approach based on a moral ideal whose ultimate goal is the respect of the person's dignity as well as the preservation of humanity. Watson points out that the individual's contribution to healthcare is determined by how well nurses translate this moral ideal in their daily practice. Adapted to administration, the transpersonal relationship can also enable higher level nurse managers to accompany FLNMs, to be with them, and to help them better describe and perceive the elements that can influence (favorably and unfavorably) their QWL 
perceptions.

To our knowledge, the task of managing care in public healthcare systems continues to be performed under difficult circumstances and, based on our review of the literature; there seem to be no instruments for specifically measuring QWL of FLNMs. Moreover, most of the qualitative and quantitative studies reviewed focused primarily on concepts adjacent to QWL (e.g., attraction, retention, work environment, and professional satisfaction). This observation underscores the fact that very little research has ever investigated the concept of QWL with respect to FLNMs. Finally, and along with Brousseau's ${ }^{[15]}$ qualitative study results, both theoretical frameworks, O'Brien-Pallas and Baumann's Quality of nursing worklife's model and Watson's Human Caring theory, have been used for the development of the new instrument to explore the factors that can influence or not the QWL among FLNMs in different sectors of the French Canadian Healthcare setting.

\section{Methods}

\subsection{Aims and objectives}

The research objectives of this quantitative descriptive study were to: (i) identify and measure the favorable and unfavorable factors that might influence QWL of FLNMs working in different healthcare institutions in Quebec; (ii) examine the relationship between sociodemographic characteristics of respondents and choice of favorable and unfavorable factors that might influence QWL of FLNMs working in different healthcare institutions.

\subsection{Study design}

A quantitative descriptive online survey was conducted during one month using a purposive sample of FLNMs in affiliated university hospitals in Quebec, Canada.

\subsection{Participants}

Participants were recruited using a purposive sampling all over the Quebec province. The population under study was selected according to the following criteria: 1) full or parttime FLNMs; 2) French spoken; 3) supervised staff nurses; 4) managed department budget; and 5) consented to complete online quantitative survey voluntarily. Based on the inclusion criteria, the primary target population (797 FLNMs) of the research represented the FLNMs working in the different sectors of activity of the institutions of the Quebec public healthcare system, including University Hospital Center (UHC), Health and social services centre (HSSC), Universityaffiliated hospital (UAH) and Rehabilitation Centers (RC).
A total of 797 emails including the questionnaire was send to FLNMs working in various areas of healthcare settings. After two email reminders, the response rate reached $37.9 \%$ (291/795 FLNMs). According to McPeake et al., ${ }^{[14]}$ this could be considered a highly satisfactory result for an online survey.

\subsection{Measurement}

The structured questionnaire - the French version of the Factors influencing quality of worklife of first-line nurse managers in healthcare institutions (FIQWL) including a demographic questionnaire for individual and professional variables - were used for collecting the data for the purpose of this research. ${ }^{[15]}$ The sociodemographic section of the questionnaire was composed of eight questions serving to gather sociopersonal, professional and organizational data needed to define the target population's profile. The second section consisted of 48 items rated on a five-point scale (1 $=$ not at all; $2=$ a little; $3=$ moderately; $4=$ a lot; and 5 = completely). The purpose of the items was to determine how respondents perceived the theoretical constructs in order to identify the factors that might influence their QWL as FLNMs. This self-administered online French questionnaire, comprised of 59 items, was developed. In 2017, this new instrument entitled: "Factors influencing the quality of work life among first line nurse managers" developed by Brousseau (c) have been translated in English (see in Appendix).

\subsection{Data collection}

Of the 797 email addresses obtained by the Quebec Board of Nursing (QBN), two proved invalid, which reduced the initial sample to 795 FLNMs. First, invitation emails containing an info-letter (project summary) and a hyperlink to the online survey were sent to participants $(\mathrm{n}=795)$ on May 9,10 , and 13, 2013. The data collection period spanned from May 9 to 30,2013 , during which time two reminders were sent out (May 22 and 27) to maximize the response rate. ${ }^{[16]}$

\subsection{Data analysis}

Statistical analyses were performed with SPSS version 22 for Windows 7. First, the Cronbach's alpha coefficients $(\alpha)$ were calculated to determine the psychometric properties of the new instrument and were calculated for all survey items. Cronbach alpha was used to complete the reliability analysis of the questionnaire. Finaly, descriptive analyses were carried out to determine respondents' sociodemographic characteristics (see Table 1). 
Table 1. Sociopersonal, Professional and Organizational Characteristics (95\% CI) of Survey Respondents vs. OIIQ FLNM

\begin{tabular}{|c|c|c|c|c|c|}
\hline \multirow{2}{*}{ Characteristics } & \multicolumn{3}{|c|}{ Respondents $(N=291)^{*}$} & \multicolumn{2}{|c|}{ OIIQ $(N=2,577)^{* *}$} \\
\hline & & $N$ & $\%$ & $N$ & $\%$ \\
\hline Age (years) & $\begin{array}{l}M=46 \\
(S D=9.1)\end{array}$ & 285 & & \multicolumn{2}{|c|}{$M=48.3$} \\
\hline \multicolumn{6}{|l|}{ Gender } \\
\hline Man & & 63 & 21.8 & 525 & 20.4 \\
\hline Woman & & 226 & 78.2 & 2,052 & 79.6 \\
\hline Marital Status & & \multicolumn{2}{|l|}{289} & & \\
\hline Single & & 23 & 8 & N/A & N/A \\
\hline Living in common law & & 90 & 31.1 & N/A & N/A \\
\hline Married & & 134 & 46.4 & N/A & N/A \\
\hline Divorced & & 29 & 10 & N/A & N/A \\
\hline Separated & & 6 & 2.1 & N/A & N/A \\
\hline Single parent & & 7 & 2.4 & N/A & N/A \\
\hline Number of children & $\begin{array}{l}M=1.86 \\
(S D=1.2)\end{array}$ & 288 & & N/A & N/A \\
\hline Level of profess. devel. & & 289 & & & \\
\hline Graduate & & 123 & 42.6 & 633 & 24.6 \\
\hline Bachelor's & & 104 & 36 & 910 & 35.3 \\
\hline Certificate & & 33 & 11.4 & 430 & 16.7 \\
\hline Quebec college diploma & & 29 & 10 & 604 & 23.4 \\
\hline Years of experience & $\begin{array}{l}M=10.43 \\
(S D=9.2)\end{array}$ & 286 & & N/A & N/A \\
\hline Title of position held & & 287 & & N/A & N/A \\
\hline Head nurse & & 161 & 56.1 & N/A & N/A \\
\hline Care activities coordinator & & 90 & 31.4 & N/A & N/A \\
\hline Health program head & & 26 & 9.0 & N/A & N/A \\
\hline Other & & 10 & 3.5 & N/A & N/A \\
\hline Number of employees & $\begin{array}{l}M=120 \\
(S D=151.8)\end{array}$ & 280 & & N/A & N/A \\
\hline Practice setting (public) & & 285 & & & \\
\hline HSSC & & 198 & 69.5 & 1,440 & 55.9 \\
\hline $\mathrm{UH}$ & & 56 & 19.6 & 317 & 12.3 \\
\hline AUH & & 28 & 9.8 & 229 & 8.9 \\
\hline $\mathrm{RC}$ & & 3 & 1.1 & 13 & 0.5 \\
\hline \multicolumn{2}{|l|}{ Other institution } & & & 591 & 22.4 \\
\hline \multicolumn{2}{|l|}{ Type of organizational structure } & 289 & & N/A & N/A \\
\hline Client prog. & & 196 & 67.8 & N/A & N/A \\
\hline Traditional & & 93 & 32.2 & N/A & N/A \\
\hline Number of units or departments & $\begin{array}{l}M=5.0 \\
(S D=12.5)\end{array}$ & 282 & & N/A & N/A \\
\hline
\end{tabular}

*Some data regarding respondent characteristics missing; ${ }^{* *}$ Available comparative statistical data from OIIQ; The survey being anonymous, it was not possible to identify the FLNM that completed the questionnaire. Consequently, the QON's sample includes the survey respondents.

\section{RESUlts}

\subsection{Sample characteristic}

The majority of the respondents (75\%) answered the 48 items concerning QWL and the 11 sociodemographic questions. There were very few missing data (8 to 11 per questionnaire) and these had little apparent impact on the quantitative results as a whole. ${ }^{[17]}$ Comparing the sociodemographic data from respondents against those provided by the QBN on its membership showed proportions to be similar in terms of gender and mean age, which minimized potential selection biases. However, where highest level of completed professional development was concerned, there were proportionally more 
respondents $(42 \%)$ with a graduate degree, proportionally fewer with a certificate or a Quebec college diploma, and almost just as many with a bachelor's degree. As for practice setting, there were proportionally more respondents working in a HSSC and a UH, and a similar proportion working in an $\mathrm{AUH}$ and in a RC. It should be noted that, as the number of FLNMs working in RC was small $(n=3)$, these respondents were excluded from the statistical analyses. The data regarding the sociodemographic characteristics of the 291 respondents are presented in Table 1.

Table 1 exposes the sociodemographic characteristics of the 291 respondents. Table 2 presents the mean scores for each of the favorable and unfavorable factors examined, according to the response scale used, ranging from 1 (not at all) to 5 (completely).

Table 2. Statistical Data on Mean Scores (favorable and unfavorable factors to QWL)

\begin{tabular}{|c|c|c|c|c|c|}
\hline & $n$ & Min. & Max. & $\overline{\boldsymbol{x}}$ & $s$ \\
\hline \multicolumn{6}{|l|}{ Factors favorable (FF) to QWL } \\
\hline $\begin{array}{l}\text { Actualization of leadership and } \\
\text { political skills to improve } \\
\text { quality of nursing }\end{array}$ & 280 & 2.00 & 5.00 & 3.99 & 0.54 \\
\hline $\begin{array}{l}\text { Contextual elements conducive } \\
\text { to organizational humanization }\end{array}$ & 282 & 1.73 & 5.00 & 3.97 & 0.60 \\
\hline $\begin{array}{l}\text { Organizational support } \\
\text { promoting personal and } \\
\text { socio-professional fulfillment }\end{array}$ & 283 & 1.20 & 5.00 & 3.96 & 0.63 \\
\hline $\begin{array}{l}\text { Learning organization } \\
\text { facilitating development of } \\
\text { nursing management } \\
\text { competencies }\end{array}$ & 275 & 1.67 & 5.00 & 3.72 & 0.66 \\
\hline $\begin{array}{l}\text { Personalized coaching meeting } \\
\text { specific needs of novice nurse } \\
\text { managers }\end{array}$ & 281 & 1.00 & 5.00 & 3.52 & 0.80 \\
\hline \multicolumn{6}{|l|}{ Factors unfavorable (UF) to QWL } \\
\hline Organizational dehumanization & 281 & 1.60 & 5.00 & 3.91 & 0.73 \\
\hline $\begin{array}{l}\text { Unfavorable working conditions } \\
\text { in nursing management }\end{array}$ & 280 & 1.50 & 5.00 & 3.78 & 0.66 \\
\hline $\begin{array}{l}\text { Insufficient coaching of novice } \\
\text { nurse managers }\end{array}$ & 284 & 1.00 & 5.00 & 3.56 & 0.67 \\
\hline Factors global score & 283 & 2.27 & 4.98 & 3.84 & 0.54 \\
\hline
\end{tabular}

The results suggest respondents ascribed a great deal of importance to the first three factors favorable to QWL and to the first factor unfavorable to QWL. Indeed, the need to update leadership and policy skills to improve the quality of nursing care; (FF1: 3.99), as did the contextual factors conducive to humanizing the organization; (presence of humanistic values) (FF2: 3.97), and the organizational support needed to foster socio-professional and personal development (FF3: 3.96). The organizational dehumanization (UF1: 3.91) was the most important unfavorable factor to influence QWL. As for the learning organization, to encourage the development of nursing management skills (FF4: 3.72) and the condi- tions unfavorable to practice of nursing management (UF2: 3.78), results showed FLNMs ascribed a moderate degree of importance to these two factors in connection with QWL, compared with the other factors. Regarding the remaining two factors (one favorable, one unfavorable), namely, the personalized support addressing the specific needs of new nursing managers (FF5: 3.52) and the insufficient personalized support for novice nurse managers (UF3: 3.56), they obtained relatively lower mean scores than the other factors did. Nevertheless, they still had a moderate influence on QWL.

Table 3. Reliability of Questionnaire with a 95\% CI for Each Eidos-Theme

\begin{tabular}{|c|c|c|c|c|}
\hline & $\begin{array}{l}\text { Cron.'s } \\
\text { alpha }\end{array}$ & $\begin{array}{l}\text { No. of } \\
\text { items }\end{array}$ & Lower & Upper \\
\hline \multicolumn{5}{|l|}{ Factors favorable (FF) to QWL } \\
\hline $\begin{array}{l}\text { Actualization of leadership and } \\
\text { political skills to improve } \\
\text { quality of nursing }(n=278)\end{array}$ & .763 & 5 & .716 & .804 \\
\hline $\begin{array}{l}\text { Contextual elements conducive } \\
\text { to organizational humanization } \\
(n=270)\end{array}$ & .873 & 11 & .849 & .894 \\
\hline $\begin{array}{l}\text { Organizational support } \\
\text { promoting personal and } \\
\text { socioprofessional fulfillment } \\
(n=279)\end{array}$ & .779 & 5 & .735 & .817 \\
\hline $\begin{array}{l}\text { Learning organization } \\
\text { facilitating development of } \\
\text { nursing management } \\
\text { competencies }(n=275)\end{array}$ & $.671^{*}$ & 3 & .598 & .733 \\
\hline $\begin{array}{l}\text { Personalized coaching meeting } \\
\text { specific needs of novice nurse } \\
\text { managers }(n=273)\end{array}$ & .767 & 4 & .718 & .809 \\
\hline \multicolumn{5}{|c|}{ Factors unfavorable (UF) to QWL } \\
\hline $\begin{array}{l}\text { Organizational dehumanization } \\
(n=272)\end{array}$ & .884 & 10 & .863 & .904 \\
\hline $\begin{array}{l}\text { Unfavorable working } \\
\text { conditions in nursing } \\
\text { management ( } n=273 \text { ) }\end{array}$ & .709 & 6 & .652 & .759 \\
\hline $\begin{array}{l}\text { Insufficient coaching of novice } \\
\text { nurse managers }(n=279)\end{array}$ & $.652^{*}$ & 4 & .581 & .714 \\
\hline All 48 items (global score) & .954 & 48 & .945 & .962 \\
\hline
\end{tabular}

\subsection{Reliability of questionnaire}

Table 3 presents the Cronbach's alpha coefficients $(\alpha)$ with a $95 \%$ confidence interval (CI) (lower and upper limits) for each favorable and unfavorable factor. This analysis was carried out to gain a better appreciation of the instrument's consistency. For the 48 items ( $n=270$ to 279 ), the global Cronbach's alpha coefficient stood at .95 , just above the result obtained in the second phase, which is considered excellent for a new instrument according to Dillman et al. ${ }^{[16]}$ 
Finally, analyses of variance, paired comparisons, post-hoc tests, and Pearson's correlation coefficients (r) were run to verify mean score differences between respondents and to determine whether the explanatory variables (sociopersonal, professional, and organizational) influenced the choice of factors favorable and unfavorable to QWL. ${ }^{[18]}$

\subsection{Ethical approval}

This study was approved by the Scientific Review Committee of the Faculty of Nursing of the Université de Montréal and the REC of the AUH. Numbers were assigned to respondants in order to respect the anonymity and confidentiality of the information collected. The collected data were coded numbers entered into the IBM SPSS statistic for Windows 7 version 22.0. ${ }^{[19]}$

\section{Discussion}

\subsection{Factors favorable to QWL}

FF1. Actualization of leadership and political skills to improve quality of nursing

The survey respondents felt it was essential to actualize their leadership and political skills in order to improve the quality of nursing offered to clients (high score of 3.99/5). The quantitative results suggest this aspect contributes considerably to their QWL. This is congruent with findings of Kelly et al. ${ }^{\text {[20] }}$ to the effect that recognition of the leadership expertise of FLNMs was a sine qua non for their retention and health at work. Moreover, in a quantitative secondary analysis study measuring the practice of leadership, Kendall ${ }^{[21]}$ asserted that upper management that fostered empowerment generated in FLNMs a sense that they managed their care unit or department effectively and performed their work at high levels. These authors have argued that better knowledge of the strategic and political jousting that is part of the negotiation and decision-making process was necessary to be able to defend or advocate for or against nursing-related issues.

\section{FF2. Contextual elements conducive to organizational hu- manization}

The results of the survey showed that respondents ascribed a good deal of importance to this QWL-related factor (high score of 3.97/5). The FLNMs (participants and respondents) deemed the presence of humanistic values in management vital for good QWL. Both qualitatively and quantitatively, they perceived that a balanced work environment (healthy and flexible), management based on humanism, humor at work, and presence of humanistic values throughout the organization could exert a positive influence on QWL. The results to emerge from this study shed new light on the importance of humanistic practices for maintaining and foster- ing professional satisfaction among FLNMs. This finding is consistent with the results of qualitative studies by $\mathrm{Cara}^{[22]}$ as well as of Duffy's work ${ }^{[23]}$ regarding caring relationships in management. A work environment that manifests caring attitudes (e.g., active listening, being present to others, helping colleagues in problem situations) and behaviors (e.g., encouraging staff and colleagues, establishing relationships of trust, recognizing work accomplished, involving FLNMs in decisions) in the practice of management favored their QWL.

FF3. Organizational support promoting personal and socioprofessional fulfillment

This third favorable factor demonstrated to be of great importance for improving the QWL of FLNMs (high score of 3.96/5), corroborates those of the quantitative study by Labrague et al. ${ }^{[24]}$ and of the qualitative study by Olender. ${ }^{[25]}$ These authors demonstrated that FLNMs perceived organizational support as a positive factor conductive to a sense of professional satisfaction and worth. This result also converges with the findings of the correlational study by Robaee, Foroozan, Atashzadeh-Shoorideh, Tahereh, Ahmadreza, and Maasoumeh Barkhordari-Sharifabad ${ }^{[26]}$ to the effect that positive organizational support contributed significantly to FLNMs work engagement and generated a sense of personal achievement. Moreover, according to Solbakken, Bergdahl, Rudolfsson and Bondas, ${ }^{[27]}$ genuine, encouraging, comforting, and reassuring support between the various healthcare professionals, including FLNMs, is considered a beneficial factor in maintaining a harmonious and quality therapeutic environment.

FF4. Learning organization facilitating development of nursing management competencies

This fourth favorable factor had a moderate influence on QWL of FLNMs (score of 3.72/5). The results of the present study also corroborate the work of Payne-Gagnon, Fortin, Paré, Côté, and Courcy ${ }^{[28]}$ on learning organization. These authors found that participating in reflexive exchanges based on lived experiences served to improve the problem-solving competencies of professionals. In this regard, Olender ${ }^{[25]}$ demonstrated that the role transformation of FLNMs had to rest on innovation and the development of knowledge and skills (nursing, caring, clinical, and administrative) to be able to resolve complex management situations freely. This knowledge helps FLNMs address complex phenomena more effectively and deal better with the healthcare system's existing deficits.

FF5. Personalized coaching meeting specific needs of novice nurse managers 
This last favorable factor shown to be a moderate contributor to QWL (score of 3.52/5). This sort of accompaniment takes the form primarily of active participation in management succession programmes, the presence of role models, and implementation of a welcome and orientation day for new FLNMs. ${ }^{[29]}$ In line with points raised in other works reviewed on the subject, the results of the present study suggest that healthcare organizations must place greater importance on providing accompaniment that meets the needs of novice FLNMs. Goodyear and Goodyear ${ }^{[30]}$ recognized that mentoring the next generation of FLNMs necessitated efforts structured by orientation activities and role models in order for novices to properly assume the different facets of a role that implies managing human, material, financial, and information resources. These authors added that orientation activities (mentoring and coaching) were winning conditions in planning the management labor force of tomorrow to attract and retain the next generation of nurses in the field of management. ${ }^{[29]}$

\subsection{Factors unfavorable to QWL}

\section{UF1. Organizational dehumanization}

Participants deemed that dehumanizing practices contributed negatively to QWL (3.91/5): this was the most unfavorable factor. The FLNMs perceived that dehumanization could be of great harm to well-being and could prove devastating for QWL. Moreover, dehumanizing practices (e.g., relationships marked by conflict and disrespect, bureaucratic red-tape, uncivil behavior, verbal and physical violence) in management could have detrimental consequences for the retention of next-generation nurse managers. The results of this study converge with those obtained by Avoine ${ }^{[31]}$ with rehabilitation patients and Brousseau, Cara and Blais ${ }^{[32]}$ with FLNMs. These authors bear witness to the fact that this type of practice can reduce the well-being of nurses, inpatients, and FLNMs in the long run. In addition, dehumanization can thwart the achievement of a moral ideal in nursing administration. Accordingly, dehumanizing attitudes and behaviors accentuate the precariousness of QWL of FLNMs, particularly when relationships are marked by conflict and disrespect. ${ }^{\text {[23,33-35] }}$ Haslam and Loughnan ${ }^{[36]}$ argued that a culture of laxity in the executive echelons toward violent behavior between staff and management does nothing but exacerbate the recurrence of such insidious phenomena in healthcare organizations. The results of our study suggest that a sense of being abandoned by or isolated from upper management and a lack of attention and communication, combined with a viscous bureaucracy, lead directly to a considerable decline in the professional development of FLNMs. ${ }^{[32]}$

UF2. Unfavorable working conditions in nursing manage- ment

This second unfavorable factor translates into barriers to the clinical-administrative practice of nursing, an imbalance between work, family, and social life, as well as an unhealthy and unsafe work environment. The high score of 3.78/5 obtained by the respondents in the quantitative phase seems to provide evidence that FLNMs perceive a decline in QWL in the absence of adequate work conditions. This corroborates the results of the correlational quantitative study by Kendall $^{[21]}$ related to the effects of high ratio staff nurse supervision on FLNMs, and those of the feminist study by Paliadelis. ${ }^{[6]}$ These authors concluded that a high level of supervision for FLNMs and increased difficulties related to ambiguity in administrative practice created a sense of ambivalence about roles and responsibilities and left little room for exercising transformational leadership. Likewise, our results coincided with the work of Panari, Levati, Bonini, Tonelli, Alfieri and Artioli, ${ }^{[37]}$ which mentionned that deterioration in practice conditions can have harmful effects on the decision-making process of FLNMs in the course of their work.

\section{UF3. Insufficient coaching of novice nurse managers}

The respondents perceived this factor to have a negative influence on their QWL (moderate score of 3.52/5). This is consistent with the study by Buffenbarger, ${ }^{[38]}$ which found that a lack of coaching and mentoring, in the course of role transition from staff nurse to nurse manager, could generate frustration in novice nurse managers. It is also in line with the concept analysis of succession planning carried out by Titzer et al., ${ }^{[39]}$ which revealed that lack of accompaniment for novice FLNMs brought about a sense of discouragement and devaluation, leading them to quit their managerial position in short order. Finally, the results of this study corroborate those of the qualitative study of generation X by Keys, ${ }^{[7]}$ who reported that a sense of abandonment experienced by novice FLNMs had a considerable detrimental impact on their socioprofessional fulfillment.

\subsection{Limitations of study}

This study presents some limitations that could not be avoided. The internal consistency of the measuring tool suggests some adjustment of the instrument with a Cronbach's alpha of 95 . However, some items proved weaker in the second and third phases (see Tables 2 and 3). These limitations might be explained by the similarity of items for certain factors favorable and unfavorable to QWL. However, not all this diminishes the validity of the findings of this study. 


\subsection{Implications for policy, education, practice, and re-} search

According to these results, we invite healthcare organizations to adopt QWL and policies to provide information on nursing management humanistic practices. This is a very important attraction and retention factor for nurses aiming to become FLNMs. Healthcare organizations would greatly benefit in adopting a humanistic workplace programme to optimize the QWL among FLNMs, such as an orientation programme for novice nurses in nursing management, or supporting systems such as effective and efficient mentoring and coaching approaches. ${ }^{[15]}$ Furthermore, healthcare administrators must maximize the development of knowledge and skills in nursing management by investing needed time and resources in advanced training programmes that will respond to the FLNMs' needs and be of great value for both novices and experts. ${ }^{[10]}$ An ongoing training programme would most likely provide human resources, financial and technological needed skills while decreasing stress and uncertainty among these health professionals. Future qualitative research, such as an action research, should be conducted among FLNMs to explore the problem they are facing as novices or experts, in addition to determine their inputs for the elaboration of appropriate strategies into their administration practice that could be implemented to improve their global QWL.

\section{Conclusion}

The main conclusion to spring from this research is that, in order to improve QWL of FLNMs, it is necessary to implement strategies informed by both favorable and unfavorable fac- tors that emerged from its quantitative component. Given the impact of the favorable and unfavorable factors in question on QWL of FLNMs, we invite decision-makers to develop a systemic policy of the humanistic quality of worklife in the healthcare system. By so doing, they could catalyze the implementation of new concrete and human-centered strategies to attract the next generation of nurses to nursing management positions based on humanistic fundamentals and values that are important to upcoming FLNMs.

Notes: This new questionnaire can serve for future research in nursing management as long as it gets the approval of the principal author of this article.

\section{ACKNOWLEDGEMENTS}

The lead author would like to thank the following funding organizations for their financial support in regards to this study: The Faculty of Nursing of the Université de Montréal, the Centre for Training and Expertise in Nursing Administration Research (FERASI) of the Université de Montréal, the Quebec Government (Ministère de l'éducation, du loisir et du sport (MELS)), the Faculty of graduate and postdoctoral studies of the Université de Montréal, as well as the Canadian Nurses Foundation. He would also like to express his gratitude to Dr. Sylvie Dubois and Dr. Mélanie LavoieTremblay for their insightful comments towards this paper. For questions about the model, you can reach the main author at the following address: sylvain.brousseau@uqo.ca

\section{CONFlicts of INTEREST Disclosure}

The authors declare they have no conflicts of interest.

\section{REFERENCES}

[1] Vogenberg FR, Santilli J. Healthcare Trends for 2018. Am Health Drug Benefits. 2018; 11(1): 48-54.

[2] Levin J. Healthcare Reform $\neq$ Public Health Reform: On Pathogens, Poverty, and Prevention. Global Advances in Health and Medicine. 2018; 7: 1-5. PMid:29435386. https://doi .org/10.1177/2164 957X18756307

[3] Brown P, Fraser K, Wong CA, et al. Factors influencing intentions to stay and retention of nurse managers: A systematic review. Journal of Nursing Management. 2013; 21: 459-472.

[4] Delamater L, Hall N. Charge nurse development: What does the literature say? Nursing Management. 2018; 49(7): 34-40. https : //doi.org/10.1097/01. NUMA.0000538914.53159.fc

[5] Shirey MR, Ebright PR, McDaniel A. Nurse manager cognitive decision-making amidst stress and work complexity. Journal of Nursing Management. 2013; 21(1): 17-30.

[6] Paliadelis PS. Nurse managers don't get the corner office. Journal of Nursing Management. 2012; 1: 1-10. https://doi.org/10.111 $1 / j .1365-2834.2012 .01405 \cdot x$
[7] Keys Y. Looking ahead to our next generation of nurse leaders: Generation X nurse managers. Journal of Nursing Management. 2014; 22: 97-105. PMid:24383465. https://doi.org/10.1111/jonm .12198

[8] Laschinger HKS, Wong CA, Macdonald-Rencz S, et al. Part 1: The influence of personal and situational predictors on nurses' aspirations to management roles: Preliminary findings of a national survey of Canadian nurses. Journal of Nursing Management. 2013; 21: 217230. PMid:23409772. https://doi.org/10.1111/j.1365-283 $4.2012 .01452 . \mathrm{x}$

[9] Skagert K, Dellve L, Ahlborg G. A prospective study of managers' turnover and health in healthcare organization. Journal of Nursing Management. 2011; 20: 889-899. PMid:23050622. https : //doi.org/10.1111/j.1365-2834.2011.01347.x

[10] American Nurses Association. Nursing administration: Scope and standards of practice. 2nd ed. Silver Spring, MD: Nurses books.org; 2016.

[11] O'Brien-Pallas L, Baumann A. Quality of nursing worklife issues: A unifying framework. Canadian Journal of Nursing Administration. 1992; 5(2): 12-16. 
[12] Watson J. Human Caring science. A theory of nursing. 2nd ed. Boulder, CO: Jones \& Barlett Learning; 2012.

[13] Watson J. Unitary Caring Science: The Philosophy and Praxis of Nursing. Louiseville, CO: University Press of Colorado; 2018.

[14] McPeake J, Bateson M, O'Neill A. Electronic surveys: How to maximise success. Nurse Researcher. 2014; 21(3): 24-26. PMid:24460562. https://doi.org/10.7748/nr2014.01.21.3 $.24 . \mathrm{e} 1205$

[15] Brousseau S. Experiential meaning and factors that influence quality of worklife of first-line nurse managers in a healthcare institution. Université de Montréal, Montreal, QC: Unpublished doctoral thesis; 2015.

[16] Dillman DA, Smyth JD, Christian LM. Internet, mail, and mixedmode surveys: The tailored design method. Hoboken, NJ: Wiley \& Sons; 2009.

[17] Polit DF, Beck CT. Essentials of nursing research: Appraising evidence for nursing practice (9th ed.). Philadelphia: Wolters Kluwer Health /Lippincott Williams \& Wilkins; 2017.

[18] Tabachnik BG, Fidell LS. Using multivariate statistics. 6th ed. Boston, MA: Pearson; 2013.

[19] IBM Corp. IBM SPSS Statistics for Windows 7, Version 22.0. Armonk, NY: IBM Corp; Released 2013.

[20] Kelly LA, Wicker TL, Gerking RD. The relationship of training and education to leadership practices in first-line nurse leaders. Journal of Nursing Administration. 2014; 44(3): 158-163. PMid:24531288. https://doi.org/10.1097/NNA.0000000000000044

[21] Kendall JM. Nurse Manager Span of Control and the Impact on Employee Engagement. University of Kentucky. UKnowledge: Unpublished doctoral thesis; 2018.

[22] Cara C. Managers' subjugation and empowerment of caring practices: A relational caring inquiry with staff nurses. University of Colorado, Health Science Center, CO: Unpublished doctoral thesis; 1997.

[23] Duffy J. Quality caring in nursing and health systems. Implications for clinicians, educators, and leaders. New York, NY: Springer Publishing Company; 2018.

[24] Labrague L, McEnroe Petitte DM, Tsaras K. Perceptions of organizational support and its impact on nurses' job outcomes. Nursing Forum. 2018. PMid:29693264. https://doi.org/10.1111/nuf.12260

[25] Olender LD. The Relationship Between and Factors Influencing Staff Nurses' Perceptions of Nurse Manager Caring and Exposure to Workplace Bullying in Multiple Healthcare Settings. Journal of Nursing Administration. 2017; 47(10): 501-507. PMid:28957868. https://doi.org/10.1097/NNA.0000000000000522

[26] Robaee N, Atashzadeh-Shoorideh F, Ashktorab T, et al. Perceived organizational support and moral distress among nurses. BMC Nursing. 2018. https://doi.org/10.1186/s12912-017-0270-y

[27] Solbakken R, Bergdahl E, Rudolfsson G, et al. International Nursing: Caring in Nursing Leadership-A Meta-ethnography From the Nurse Leader's Perspective. Nursing administration quarterly. 2018; 42(4): E1-E19. PMid:30180085. https://doi .org/10.1097/NA Q.0000000000000314
[28] Gagnon MP, Payne-Gagnon J, Fortin JP, et al. A learning organization in the service of knowledge management among nurses: A case study. International Journal of Information Management. 2016; 35: 636-642. https://doi.org/10.1016/j.ijinfomgt.2015.05.001

[29] Brousseau S, Cara C, Blais R. Experiential meaning of a decent quality of work life for nurse managers in a university hospital. Journal Hospital Administration. 2016; 5(5): 41-52. https: //doi.org/10.5430/jha.v5n5p41

[30] Goodyear C, Goodyear M. Supporting successful mentoring. Nursing Management. 2018; 49(4): 49-53. PMid:29596143. https: //doi.org/10.1097/01. NUMA.0000531173.00718.06

[31] Avoine MP. The meaning of dehumanizing practices as experienced by current and past rehabilitation center inpatients. Université de Sherbrooke, Sherbrooke, QC: Unpublished Master's thesis; 2013.

[32] Brousseau S, Cara C, Blais R. A Humanistic Caring Quality of Work Life (HCQWL) model in nursing administration based on Watson's philosophy. International Journal for Human Caring. 2017; 11(2): 1-19. https://doi.org/10.20467/1091-5710-21.1.2

[33] Brousseau S. Approcher la qualité de vie au travail des cadres infirmiers de premier niveau selon une perspective humaniste. Communication présentée au premier congrès scientifique belge portant sur Les soins humanistes comme fondement de la pratique infirmière: réalité ou utopie? Que nous enseigne la recherche? Bruxelle, Belgique; 2018. Available from: https://scienceinfirmiere. weebly.c om/congregraves-8-octobre-2018.html

[34] Cara C. Les soins infirmiers humanistes pour faire la différence dans la souffrance et la déshumanisation. Communication présentée au Colloque européen « Les soins humanistes comme fondement de la pratique infirmière. Passé, présent et futur ». Lausanne, Suisse; 2018

[35] Christoff K. Dehumanization in organizational settings: Some scientific and ethical considerations. Frontiers in Human Neuroscience. 2014; 8(748): 1-5. PMid:25309401. https://doi.org/10.3389/ fnhum. 2014.00748

[36] Haslam N, Loughnan S. Dehumanization and infrahumanization. Annual Review of Psychology. 2014; 65(1): 399-423. PMid:23808915. https://doi.org/10.1146/annurev-psych $-010213-115045$

[37] Panari C, Levati W, Bonini A, et al. The ambiguous role of healthcare providers: a new perspective in Human Resources Management. Acta Bio Médica. 2016. Available from: http://www.mattioli1885journals.com/index.php/act abiomedica/article/view/5432

[38] Buffenbarger JS. Nurses' Experiences Transitioning from Staff Nurse to Management in a Community Hospital. 2016. Available from: https://pdfs.semanticscholar.org/3965/826ac7fd 24e1744de8c7dc79bc88a9760638.pdf

[39] Titzer JL, Shirey MR, Hauck S. A nurse manager succession planning model with associated empirical outcomes. Journal of Nursing Administration. 2014; 44(1): 37-46. PMid:24316617. https: //doi.org/10.1097/NNA.0000000000000019 